\title{
Dynamic Analysis of Hydraulic System of a Mobile Garbage Compression Equipment Based on AMESim
}

\author{
Yihong Zhao* \\ College of Mechanical Engineering \\ Yangzhou University \\ Yangzhou, China , 225009 \\ yihongzhao99@sina.com \\ Zhengkun Wu \\ College of Mechanical Engineering \\ Yangzhou University \\ Yangzhou, China , 225009
}

\author{
Bo Jiang \\ College of Mechanical Engineering \\ Yangzhou University \\ Yangzhou, China , 225009 \\ Ran Dong \\ College of Mechanical Engineering \\ Yangzhou University \\ Yangzhou, China , 225009
}

\begin{abstract}
The hydraulic system of mobile garbage compression equipment was studied according to its actual working conditions. A simulation model of the hydraulic system was established with AMESim software, and the speed and acceleration of the piston rod were simulated. Simulation results show that the designed hydraulic system can achieve the action requirements. The experiment also shows the similar situation.
\end{abstract}

Keywords- compression equipment; hydraulic system; dynamic analysis; AMESim

\section{INTRODUCTION}

The loading and compression of the garbage are mostly completed through the hydraulic system and the operating control system to the mobile garbage compression equipment. The hydraulic system and operating control system have a direct impact to the equipment on safety, reliability and convenience. Noise and vibration are problems which urgently need to solve to most garbage compression equipment. Improving the stability of the hydraulic system and control system is a feasible way to avoid noise nuisance [1-4].

The mobile garbage compression equipment is composed of main structure, hydraulic system and operating control system. Actions can be drawn:

A. The action of loading and unloading of the flipped bucket is completed by one pair of gears.

B. The action of compressing garbage is completed by a pushed plate.

\section{DESIGN OF HYDRAULIC SYSTEM}

According to actual conditions, the hydraulic system shown in Fig. 1 is designed. The electric motor drives the hydraulic pump to produce pressure oil, and the pressure oil of the main circuit is flowed into the flipping control circuit and the compression control circuit by the main commutation return circuit. The flipping speed control and the compression speed control are realized by the electromagnetic directional valve. When $\mathrm{K} 0$ and $\mathrm{K} 2$ are conducted, the flipping hydraulic cylinders fast forward. When $\mathrm{K} 0$ and $\mathrm{K} 4$ are conducted, the flipping hydraulic cylinders slow forward. When $\mathrm{K} 0$ and $\mathrm{K} 3$ are conducted, the flipping hydraulic cylinders fast retreat. When $\mathrm{K} 0$ and $\mathrm{K} 5$ are conducted, the flipping hydraulic cylinders slow retreat. When K1, K7 and K8 are conducted, the compression hydraulic cylinders differential fast forward, when K1, K6 and K9 are conducted, the flipping hydraulic cylinders fast retreat.

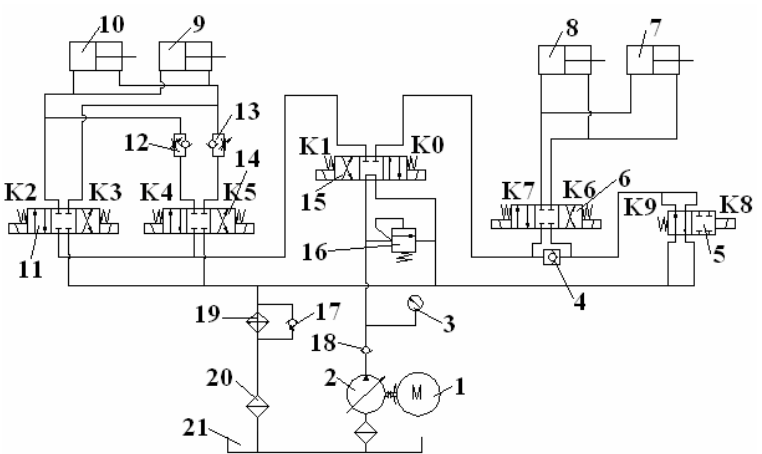

1 Electric motor; 2 Hydraulic pump; 3 Manometer; 4,17,18 One-way valve; 5

Two-position four-way electromagnetic directional valve; 6,11,14,15

Three-position four-way electromagnetic directional valve; 7,8,9,10

Hydraulic cylinder; 12,13 One-way throttle valve; 16 Relief valve; 19 Air cooler; 20 Filter; 21 Oil tank

Fig. 1. Hydraulic system diagram

\section{SYSTEM SIMULATION}

In order to verify the feasibility of the hydraulic system, the hydraulic system dynamics simulation analysis is completed based on AMESim software [5-8]. According to the hydraulic system principle and actual conditions, two simulate model are established, the flipping control circuit simulate model is shown in Fig. 2, and the compression control circuit is shown in Fig. 3. 


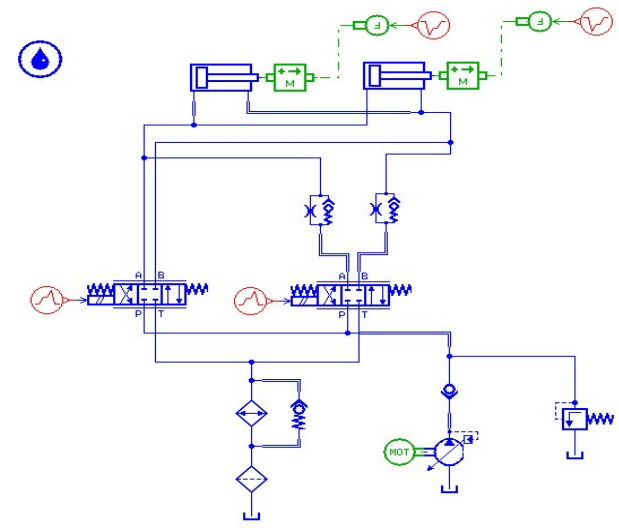

Fig. 2. Model of flipping control circuit simulation

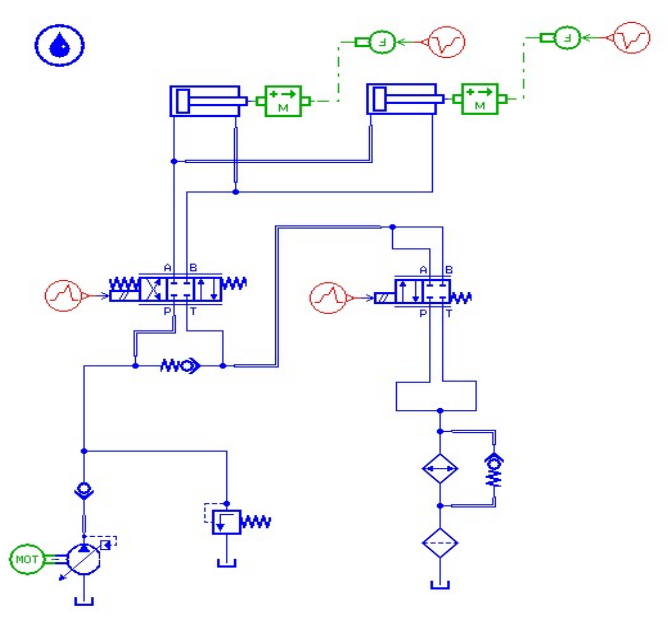

Fig. 3. Model of compression control circuit simulation

In test, the working pressure of the hydraulic system is 16MPa. The simulation parameters of hydraulic pump, electromagnetic directional valve, hydraulic cylinder and other components were set according to their respective characteristics.

Total simulation time was $16 \mathrm{~s}$, and simulation step was 0.01s. Velocity simulation curves of flipping hydraulic cylinder is shown in Fig. 4, and velocity simulation curves of compression hydraulic cylinder is shown in Fig. 5.

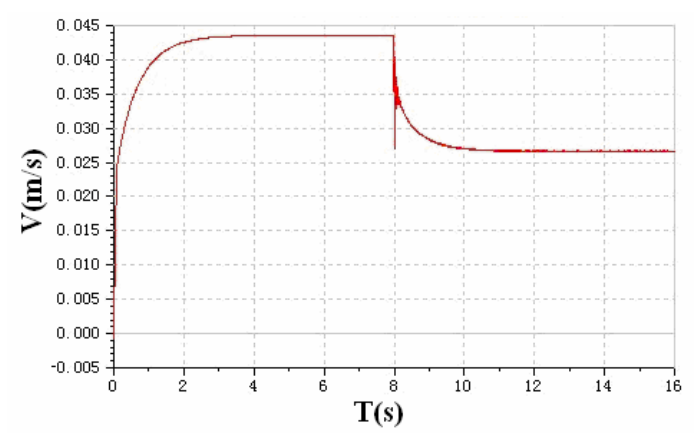

Fig. 4. Velocity simulation curves of flipping hydraulic cylinder

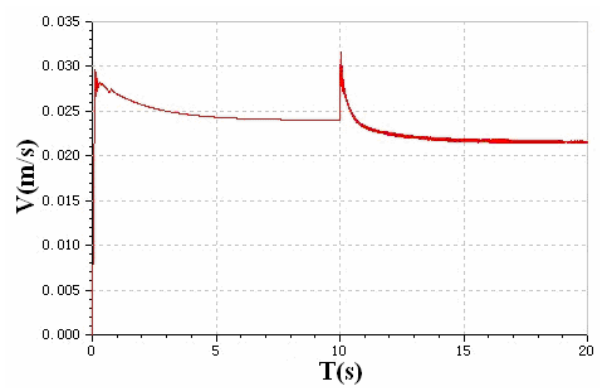

Fig. 5. Velocity simulation curves of compression hydraulic cylinder

Fig. 4 and Fig. 5 show the flipping hydraulic cylinder and the compression hydraulic cylinder run smoothly, the fast forward velocity of the flipping hydraulic cylinder reaches a stable level that is $42 \mathrm{~mm} / \mathrm{s}$. The flipping hydraulic cylinder can achieve slow forward by throttle valve. When the diameter of the throttle valve orifice is $1 \mathrm{~mm}$, the slow forward velocity of the flipping hydraulic cylinder is $18 \mathrm{~mm} / \mathrm{s}$.

When electromagnetic directional valves work, speed of the hydraulic cylinder changes in a short period of time, and it can make acceleration mutation.

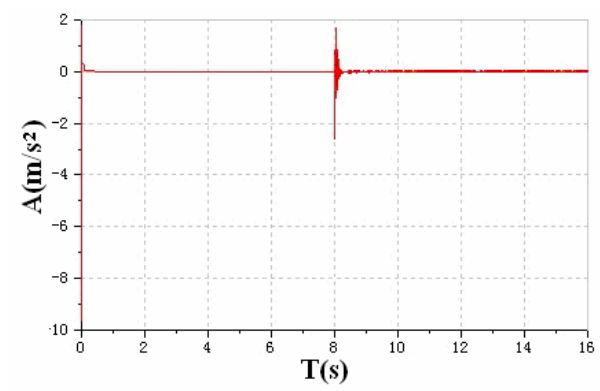

Fig. 6. Acceleration simulation curves of flipping hydraulic cylinder

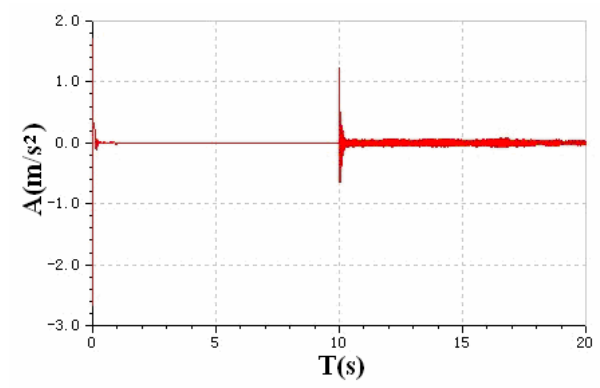

Fig. 7. Acceleration simulation curves of compression hydraulic cylinder

Fig. 6 and Fig. 7 present the acceleration simulation curves of the flipping hydraulic cylinder and the compression hydraulic cylinder. The simulation results show that a greater acceleration will be generated when the hydraulic cylinder achieved the fast forward and slow forward switching, and acceleration and inertia loads also should be generated in the beginning. The hydraulic system will have some vibration and noise in these two phases, especially in the feeding process, the flipping hydraulic cylinder can easily lead to instability and impact of operating conditions because of flipping bucket negative load and mass inertia force. The simulation results 
show that the flipping maximum acceleration can reach $12 \mathrm{~m} / \mathrm{s}^{2}$ in the start.

In order to reduce the flipping hydraulic cylinder start acceleration, the original hydraulic system is improved and shown in Fig. 8.

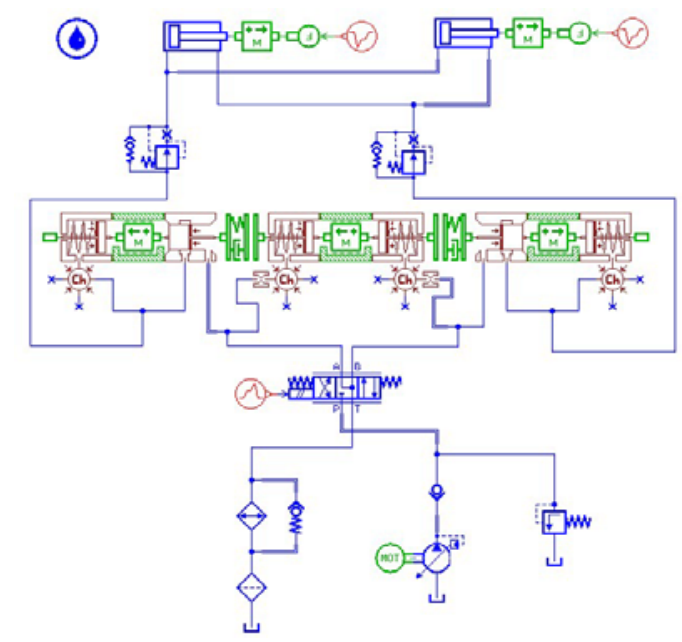

Fig. 8. Model of improved flipping control circuit simulation

The throttle valve is replaced by control valve to make the flow and speed more stable, and fluid control one-way valve is installed in oil circuit to balance circuit. The O-type electromagnetic directional valve is replaced by the Y-type electromagnetic directional valve to reduce commutation impact and to improve the lock effect of the actuator.

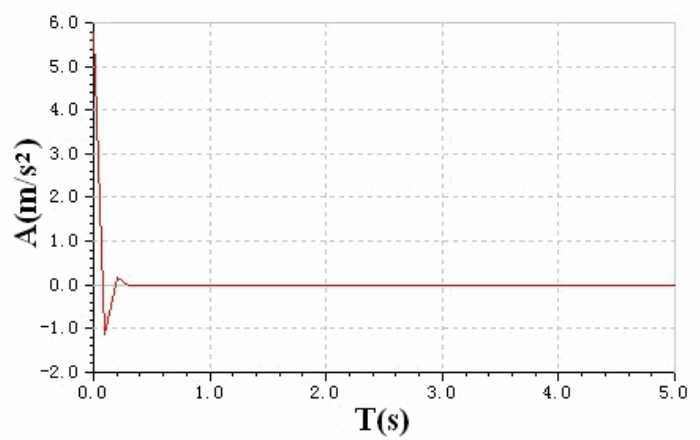

Fig. 9. Acceleration simulation curves of improved flipping hydraulic cylinder

Fig. 9 presents the acceleration simulation curve of the improved flipping hydraulic cylinder. The simulation results show that the acceleration of improved flipping hydraulic cylinder is reduced to $6 \mathrm{~m} / \mathrm{s}^{2}$, and the impact has been reduced greatly. Therefore, the improved hydraulic system runs more smoothly, and has less noise of impact and vibration.

\section{EXPERIMENTS AND ANALYSIS}

According to the principle of hydraulic system of mobile garbage compression equipment, an experimental system shown in Fig. 10 was established. The experiment results show the hydraulic system designed runs smoothly and can achieve the action requirements. The hydraulic system optimized can receive lower noise.

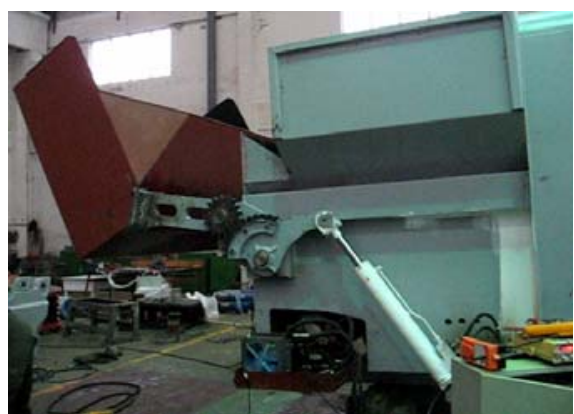

Fig. 10. Experimental system for mobile garbage compression equipment

\section{CONCLUSIONS}

In this paper, a new hydraulic system of mobile garbage compression equipment was designed according to its actual working conditions. The dynamic simulation analysis of the hydraulic system was realized with AMESim software. The main contribution of the paper is as follows:

A. Simulation results show that the designed hydraulic system can achieve the action requirements. The experiment also shows the similar situation.

B. In order to reduce the flipping hydraulic cylinder start acceleration, the original hydraulic system is optimized. The optimized hydraulic system runs more smoothly, it is verified with simulation and experiment.

These studies provide an important guiding significance to improve the stability of the hydraulic system of mobile garbage compression equipment and avoid noise nuisance.

\section{REFERENCES}

[1] X. M. Pi, Z. W. He, The design of hydraulic pressure system and PLC control system about the back-loading squeeze refuse collector, Machinery Design \& Manufacture, vol. 8, 2006, pp. 123-124.

[2] D. Y. Hao, X. Y. Wang, T. Hou, Design of hydraulic system of back-loading compression refusec ollector, Special Purpose Vehicle, vol. 6, 2010, pp. 48-51.

[3] L. J. Dong, Y. L. Cao, The development of LT5170ZYS compression garbage truck, Commercial Vehicle, vol. 6, 2005, pp. 84-86.

[4] Y. L. Cao, L. J. Dong, Development of after- loading compression- type dust cart for the city, Equipment Manufactring Technology, vol. 3, 2009, pp. 155-156.

[5] Y. S. Fu, X. Y. Qi, Q. Li, LMS Imagine.Lab AMESim system modeling and simulation reference manual, Press of Beijing University of Aeronautics and Astronautics, Beijing, 2011.

[6] J. Y. Zhao, D. S. Zhang, W. C. Lu and C. Z. Yang, Design and experiment of hydraulic impact loading system for mine cable bolt, Procedia Earth and Planetary Science, vol. 1, 2009, pp. 1337-1342.

[7] C. B. Wang, Z. Yan, Simulating research on hydraulic system of hydraulic-pressure drilling machine on the basis of AMESim, Hydraulics Pneumatics \& Seals, vol. 12, 2011, pp. 14-16.

[8] X. Y. Wang, X. X. Li, F. S. Li, Analysis on oscillation in electro-hydraulic regulating system of steam turbine and fault diagnosis based on PSOBP, Expert Systems with Applications, vol. 37, 2010, pp. 3887-3892. 